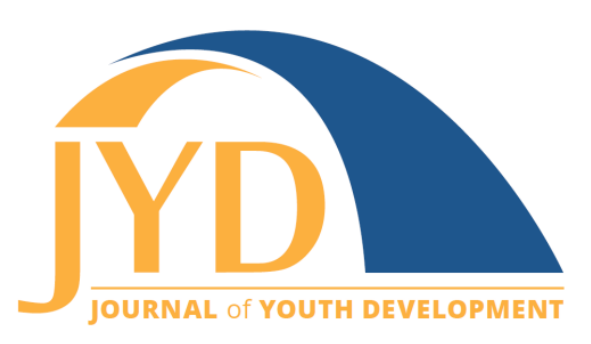

http://jyd.pitt.edu/ | Vol. 16 Issue 2-3 DOI 10.5195/jyd.2021.1034 | ISSN 2325-4017 (online)

\title{
Deconstructing the Role of Adult Facilitators in Research Led by Young People
}

\section{Patricio Cuevas-Parra}

World Vision International and University of Edinburgh

patricio_cuevas-parra@wvi.org

\begin{abstract}
Academia and practice have increased their investment in young peoples' participation. One key approach has been the shift from extracting data from young people to engaging them as researchers. Drawing on 2 case studies with young Syrian refugees and Bangladeshi young people, this paper critically reflects on the tensions between participation, power, and ethics whilst engaging young people as lead researchers. There are dual objectives to young people-led research: (a) the empowerment of young people as investigators and (b) the study of issues important to young people. If not clearly established from the outset, these objectives may be in conflict. In such projects, the process and methodology work to achieve the aims of the study and young people's participation. The achievement of both objectives of young people-led research is partially dependent on adult facilitators' support of the research process. This article explores the role of adult professionals towards achieving the goals of rigorous research and young people's participation. These tensions commonly surface in research with young people and should be addressed by employing sensitive approaches that recognise young people as competent social actors with the ability to engage in research whilst taking into consideration relevant adult engagement and support.
\end{abstract}

Key words: young people-led research, adolescent voice, child-adult collaboration, participation and protection

\section{Introduction}

Traditional research is primarily conducted by academics and professional researchers, and young people are considered only for respondent roles and unlikely to be involved as lead researchers or data collectors. A growing interest has been documented in the literature in the past few decades to put young people's views at the centre of research (e.g., Alderson and Morrow, 2004; Johnson et al., 2014; Michail and Kellett, 2015). Academia and practice have

(cc) EY New articles in this journal are licensed under a Creative Commons Attribution 4.0 License. This journal is published by the University Library System, University of Pittsburgh and is cosponsored by the University of Pittsburgh Press. The Journal of Youth Development is the official peer-reviewed publication of the National Association of Extension 4-H Youth Development Professionals and the National AfterSchool Association. 


\section{Deconstructing the Role of Adult Facilitators}

made significant advancements with opportunities for young people to participate in research and develop frameworks, methodologies, and associated tools for collaborative and ethical research with young people, especially those from the most vulnerable populations (e.g., Cuevas-Parra, 2015; Newell et al., 2012; Participation Works, 2009; Thomas, 2015; YouthPower Learning, 2020). Equally, the positive youth development (PYD) framework has contributed by highlighting the importance of creating space and opportunities for young people to access positive experiences, resources, and opportunities, which are beneficial to both young people and society as a whole (Benson et al., 2007; YouthPower Learning, 2020).

Young people's participation in research has been influenced mainly by the United Nations Convention on the Rights of the Child (UNCRC), the conceptualisation of young people as competent social actors (e.g. James \& James, 2012; Mayall, 2000; Percy-Smith, 2010; Tisdall \& Punch, 2012), and emancipatory and participatory action research (e.g. Cahill, 2007; Fleming, 2012; Skelton, 2008). From an international policy perspective, the UNCRC recognises young people-people under the age of 18-as capable individuals who can form views on matters relevant to them and able to contribute to the creation of knowledge by engaging in research (UN Committee on the Rights of the Child, 2009). From a theoretical perspective, the field of Childhood Studies established young people are social actors who have competencies and abilities to participate in shaping their environment, are active in the determination of their social lives and as participants of social structures (Prout \& James, 1990). This implies that young people are able to participate and lead research and produce knowledge based on their own experiences and expertise (James, 2007). Furthermore, the engagement of young people in research is indebted to the ideologies and methodologies developed by emancipatory research, social action research, and feminist research (e.g. Cahill, 2007; Fleming, 2012; White et al., 2004). These movements opened new avenues for non-academically trained individuals to challenge traditional research paradigms and offered new ways to generate rigorous data by including and empowering marginalised and invisible groups of people in knowledge creation (Ansell et al., 2012). Beyond these positive advances, more needs to be known and understood about the ways in which young people can actively engage in research and the role of adult facilitators in young people-led research processes. This intergenerational component brings advantages and disadvantages that must be explored. Thus, it is relevant to critically discuss the potential tensions within the scope of what their engagement entails and the way in which their participation and adults' guidance relate to one another. These components are linked, but sometimes they seem to be artificially irreconcilable opposites. Therefore, this article focuses on enlightening examples where young people's participation in research seems to surpass such tensions and addresses issues of inequality and exclusion, particularly in vulnerable populations 


\section{Deconstructing the Role of Adult Facilitators}

(e.g. Caputo, 2017; Newell et al., 2012; Yardley, 2011). In young people-led research projects, the multifaceted relationships between adult facilitators and young researchers are characterised by technical support, interpersonal connections, authority, and negotiation processes, which together construct and reconstruct the meanings of these relationships, their tensions, and challenges. Current childhood-studies literature evidences that the relational practices between young researchers and adult facilitators are complex, diverse, and evolving, and have an impact on the processes and outcomes of participatory projects, especially those which are led by young people (e.g. Shier, 2015; Thomas, 2015; Tisdall et al., 2015; Wyness, 2009).

\section{Unpacking the Concept of Young People-Led Research}

Historically, young people's views have often been silenced in research due to traditional values that perpetuate the belief that young people-as well as other social groups-lack the ability to lead research based on the supremacy of academia in knowledge generation (Anyon et al., 2018). To challenge this position, academia and practice have been exploring innovative methodologies to create spaces for young people to engage in research projects in a range of capacities, including data collectors, advisers, co-researchers, or lead researchers (e.g., Hampshire et al., 2012; Porter et al., 2012; Spalding, 2012). Even though there are different levels of participation, ranging from consultation to young people-led actions, in all types of models, the challenges are similar and commonly include tokenism, consultation without dialogue, and relational tensions between young people and adults (Tisdall, 2015). This article focuses on young people-led research, where young researchers hold the primary decisionmaking roles over adults and how this might address those restrictions.

Yet, there is not an agreed upon definition of "young people-led research," for this article, I use a definition developed collectively during a research study I conducted with World Vision. This reads as:

Young people-led research is a participatory process where young people, either with or without the support of adult facilitators, conduct pieces of research by selecting the topic, designing the tools, collecting and analysing data and providing recommendations. (Cuevas-Parra, 2015)

This definition implies that young people-led research is a form of collective participation, rather than an individual exercise, where young researchers collaborate with peers in a shared process with the joint aim of generating new knowledge and influencing decision making. That said, 


\section{Deconstructing the Role of Adult Facilitators}

individuals still are present when there are collective or participatory efforts. This echoes the UNCRC's General Comment No. 12 that shapes the right to be heard and listened to as a collective participation process that seeks to influence decision making, have an impact on young people's lives, and bring about change (Tisdall et al., 2015).

This definition also touches on one of the most prominent components of the young people-led research: All stages of the research from conceptualisation to data collection to analysis are led by the young researchers. This complete engagement is one of the most contested elements of this type of research, as this challenges conventional research practices and enables young people to participate in inquiries using their own methodologies, expertise, and experience as opposed to being told what to do. This approach is endorsed by emancipatory research scholars who argue that academia is not the only group able to generate knowledge, but when support and tools are provided to excluded groups, they too can produce (e.g. Ardoin et al., 2014; Hordijk \& Baud, 2006). Equally, other authors point out that when young people act as lead researchers they are able to obtain data from an insider perspective and can use this information to have an impact on policy issues that affect their lives and interests (Spyrou, 2011; Tisdall, 2017). This infers that young people-led research aims to generate information that can be used to provide recommendations for actions and potentially contribute to a change. This distinctive element deduces that when young people engage in research, they are not only seeking to produce knowledge per se, but they are wanting to make a difference in their lives based on the data they collect (e.g. Bessell, 2009; Sharpe, 2015; Tisdall, 2017).

\section{Young People-Led Research as Knowledge Production}

One of the fundamental questions regarding young people-led research is whether young researchers are able to produce legitimate knowledge by conducting and leading their own research (e.g. Ansell et al., 2012; Cuevas-Parra \& Tisdall, 2019; Porter et al., 2012). As framed by emancipatory and action research scholars, young people-led research offers a new ideology that challenges traditional paradigms by establishing innovative research methodologies and involving new research actors and principles (e.g. Anyon et al., 2018; Mackenzie et al., 2012; White et al., 2004).

Central to this type of research is the personal knowledge, experience, and expertise of the young researchers, in addition to the use of appropriate methodologies and capacity building. When young researchers are able to formulate their own particular views on the issues they experience in their lives, they are able to produce knowledge; it is, nevertheless, critical to 


\section{Deconstructing the Role of Adult Facilitators}

generate knowledge beyond the personal experiences of the young researchers that is also rooted in the data collected from participants (see also Ansell et al., 2012; Cahill, 2007). The legitimacy of young researchers' work is based on the fact that they are experts on their own lives; thus, their expertise and experience are foundational to the investigation process (e.g. Törrönen \& Vornanen, 2014). The claim of expertise and experience, however, should not be taken lightly or for granted as the notion of competent social actors also brings the need to examine how the young people-led research is conducted and the ethical consideration of young people's involvement. However, the claim that the research knowledge is based only on the young researchers' experiences and expertise is contested and needs to be critically discussed. This scrutiny should also cover the methods and techniques used and the understanding that young people are a diverse social group whose social competencies vary from time, space, and geographical location (see also Punch, 2012).

\section{The Role of Adult Facilitators}

One key component of the definition of "young people-led research" is the potential engagement of adult facilitators, which is the focus of this article. This states that, when young people lead a research process, from design to data analysis to findings dissemination, an adult facilitator may or may not assist them. Within this definition, the role of an adult facilitator is considered helpful, as long as they assist without managing the project and maintain the appropriate balance between the roles. This position resonates with scholars who suggest that an adult facilitator can enhance young people's abilities to carry out their own research based on mutual learning (Hampshire et al., 2012; Shier, 2015; Spalding, 2012). Equally, studies suggest that the dialogue between adult facilitators and young researchers improves research outcomes as both groups can benefit from their own experiences and understandings of the issues investigated, but there is a blurred line between respecting their own perspectives and imposing their views over others (Davis, 2009; Kina, 2012; Spyrou, 2011).

This brings to the discussion issues of power, control, and hierarchy that have been identified as critical deterrents and ongoing challenges around young people-adult relations (Alderson, 2015). In most organisational contexts where young researchers interact with adults, it was found that adults have different levels of authority and control over young people as a result of age, experience, knowledge, and social position (see also Plows, 2012 for further discussion). One of the persistent challenges of the adult facilitators' role is the tension between facilitation and management, which intersects with the ability of the young researchers to make their own decisions in research projects and shape the outcomes of their study. These challenges are 


\section{Deconstructing the Role of Adult Facilitators}

mainly associated with power relations amongst the young researchers and adult facilitators that can be determined by a number of factors, such as age difference, gender, language, education, and socioeconomic status (for further discussion see also Alanen, 2016; Konstantoni \& Emejulu, 2017; Rodó-de-Zárate, 2015). Furthermore, Pinkney (2011) argues that an additional and permanent tension is the one between participation and protection, where adult facilitators might struggle in harmonising key principles for young people's participation and safeguarding standards. In the same line of thought, Caputo (2017) points out that, in many organisational settings, there is a tendency to prioritise protection over participation, creating a sort of unbalance between rights. Failing to acknowledge and address these concerns directly affects the nature of young people-led research, which should always be a supportive and empowering environment, rather than one that is highly controlling or hierarchical. The adult support in this context needs to reflect a level of leadership and control that is wielded by the young researchers over all the stages of a research project, resulting in clear ownership by the young people of the research process (see also Shier, 2015). This echoes the PYD framework in which young people develop a sense of positive identity, including personal power, self-esteem, sense of purpose and positive view of personal future (Benson et al., 2007; YouthPower Learning, 2020)

\section{Methodology}

This article draws upon an empirical study to critically explore how the processes and outcomes of young people-led research contribute, positively or negatively, to decision-making processes in the context of international development programmes. This research was conducted by an adult researcher, closely examining research projects carried out by young researchers between the ages of 12 and 18 in Bangladesh, Jordan, and Lebanon. Two projects were selected for this study. For the purposes of this article, the author refers to the one that took place in Bangladesh as Dhaka, and the one conducted in Lebanon and Jordan as Bekaa and Irbid. The first case study, Dhaka, involved Bangladeshi young people who conducted research to explore how a lack of birth certificates amongst local children put them in a position of vulnerability and increased their risk of abuse due to the absence of legal papers. The second case study, Bekaa and Irbid, explored the engagement of Syrian refugee young people in their host countries of Lebanon and Jordan, who researched the issues that impact on children's lives whilst they try to adjust to their new countries with the hope of making a change.

This study had three research questions and this article discusses the third one: "How did young researchers perceive the role of adult facilitators as an intergenerational component of 


\section{Deconstructing the Role of Adult Facilitators}

the young people-led research project?" In order to answer this question, this research project aligns with a qualitative research paradigm, which reflects my epistemological position that reality is constructed and the understandings of the world are formed through negotiations and agreements amongst people (Blaikie, 2009). In line with this position, this research project was influenced by foundational childhood studies' tenets that reality and individual lives are socially constructed and negotiated through everyday interactions (James \& James, 2012). Throughout the research project, I took this same position, backing the perspective that there are many versions of childhood and youth that are constructed and shaped by multiple cultural, social, and political structures (Prout \& James, 1990). Equally, the design of this study reflected the PYD principles in practice, such as inherent capacity for positive growth and development; benefits from relationships, contexts, and ecologies; and support, empowerment, and engagement of young people as major actors in their own development (Benson et al., 2007). Hence, this qualitative approach supports a process that enables the young researchers to explore the experiences of the research participants in depth and allows space for interactions to understand and qualify participants' knowledge and attitudes towards the topic investigated (Ritchie \& Lewis, 2003).

Research participants included 48 young people and 14 adults. There were 26 young participants and eight adults in the Bekaa and Irbid case study, and 22 young participants and six adults from the Dhaka case study. In terms of the techniques selected, this research project adopts two methods for data collection: focus groups and semi-structured interviews. Focus groups were chosen as a method for data collection because of the interactive nature of focused group discussions that create a safe space for connection, dialogue, and dynamic engagement (Morgan, 2012). Semi-structured interviews, were employed to build a conversation in an informal style, in which the researcher and interviewee engage in a dialogue that contributes to in-depth data (Punch, 2002). The use of multiple methods facilitates the data-gathering process and enabled the researchers to investigate topics deeply and uncover some hidden aspects of the young people's narratives, which would be more challenging if just one data collection method was used (Gray, 2009). Furthermore, having multiple methods empowered the young people to choose how they wanted to participate, e.g., in individual interviews or as part of a focus group, which respects the complexity of different young people's conceptions of their worlds (Ritchie \& Lewis, 2003).

This project used a case study approach, and within this method, the most appropriate selection strategy is purposive sampling (Gray, 2009). The two case studies-Dhaka and Bekaa and Irbid-were selected as they were recognisable examples of young people leading and 


\section{Deconstructing the Role of Adult Facilitators}

conducting their own research within an international development programme context. Criteria taken into account when recruiting participants for this study were that participants (a) were involved in one of the two young people-led research projects, (b) had extensive knowledge on these processes, and (c) could provide rich information to answer the research questions.

This research project gained approval from the Research Ethics Committee at the School of Social and Political Science at the University of Edinburgh. This project adhered to key ethical considerations when conducting research with young people, including securing ongoing informed consent, ensuring the right to opt out, confirming confidentiality and anonymity, acknowledging the cultures of the research sites, and refraining from presenting information that may potentially harm participants (Alderson \& Morrow, 2004). Furthermore, for those participants below the age of 18 , consent was provided by their parents or guardians. As part of the ethical approaches, participants were asked their permission to record the interviews and focus groups, which happened only with authorisation from all participants.

Data collection and analysis were carried out directly by the adult author, and the young people acted as research participants only for the purpose of this study. The data obtained from fieldwork were organised into themes, categories, and codes and examined using thematic analysis in order to determine patterns within the data that were associated with specific research questions and the central theme of this study (Guest et al., 2012). In terms of the research questions examined in this article, the analysis identified three elements related to the engagement of adult facilitators in supporting the young researchers in their young people-led research projects. These were (a) the blurred area between support and management, (b) power and negotiation, and (c) interpersonal connections.

\section{Situating the Case Studies}

This article discusses two case studies as follows:

\section{Bekaa and Irbid Case Study}

This project was conducted in Lebanon and Jordan, where children and young people who fled Syria's civil war found refuge. These heavily war-affected groups of children and young people embarked on a participatory process to research issues that affected them in their new host countries with the support of World Vision. The young researchers led the entire research process, including the development of research questionnaires, collection and analysis of data 


\section{Deconstructing the Role of Adult Facilitators}

and prioritisation of findings in order to provide a set of recommendations on how to make change in their lives.

\section{Dhaka Case Study}

This comprised of a project conducted in Bangladesh with children and young people who were members of a local Children's Parliament supported by World Vision. A number of the members led a research project on the issue of the lack of birth certificates and its negative impact on the well-being of Bangladeshi children. The children and young people managed the project from the conceptualisation of research questions to the dissemination of their findings.

\section{Results and Discussion}

\section{The Blurred Lines Between Adult Support and Management}

A substantial claim of the proffered definition of "young people-led research" is that the potential engagement of adults is within a facilitator role in a research process that is entirely managed by young researchers from developing the research questions to data collection to report writing. In this process, the role of the adult facilitator is to provide support and guidance, but not to lead the course of actions. This raises the question of whether the participation of an adult facilitator changes the nature of a young people-led process. Data from my study shows that in both case studies—Dhaka and Bekaa and Irbid-young researchers and adult facilitators consider that the inclusion of adult facilitation does not undermine the young people-led process. They, however, acknowledge that there is always a risk of having an adult who tries to dominate the project, but, in general, they collectively agreed that the support of an adult facilitator has the potential to strengthen the research process, if done properly (e.g., support, not management; guidance, not control). The latent adult-dominated process was highlighted by the interviewees based on their experiences in previous projects where some adults tried to control their decisions and actions. Young people interviewed pointed out that adult facilitators had a critical and positive role in their research projects and the dynamic generated amongst them contributed to the success of their initiatives. The young participants, however, noted that the adult-young people relationships were intricate and often defined by power and authority over them as young people-for instance, at school and in their families and communities-but they considered the adult facilitators' role in their projects as different. One young researcher from the Bekaa and Irbid case study explained:

First, we had the freedom to say everything we want. Second, the way we were treated by the facilitators, that was excellent. And the last one, we had an easy 


\section{Deconstructing the Role of Adult Facilitators}

process to present the information and make decisions about what to include or not in the report. (Abdullah, aged 18, male, Lebanon)

This account was supported by the adult facilitators, in terms of the young peoples' expectations in their interactions with adults who were authoritarian, inflexible, and valued discipline more than any other aspect of an activity. Interviewees highlighted that this pivot in their assumption of a facilitator being an authoritarian to one who was flexible and approachable, was critical in turning the mindsets of young researchers and the way they related to their adult facilitators. Jabbar, a 12-year-old boy, from Jordan, noted: "He [the facilitator] helped us when we were not able to express ourselves. He was giving us ideas and multiples choices." In addition, these positive perceptions encouraged the young researchers to remain involved in the project as the facilitators' role assured that the project was their own research, they had control of all project stages, and facilitators supported them only in ensuring that all logical pieces came together and providing the knowledge needed to execute the research.

When asked about how they engaged with the facilitators, young researchers reported that the adult facilitators used appropriate techniques to stimulate a conducive environment that was open to debate and contributed to addressing the issues that they wanted raised. For instance, there were presentations about research skills, tools, ways to collect data and analysis and report writing. There was an agreed position amongst the young researchers that the adult facilitators were central in securing opportunities and spaces for them to express their views, experiences, and needs. Hanadi, a 16-year-old girl from Lebanon, noted: "the best was the freedom: freedom to decide, freedom to participate, freedom to think, freedom to say no." In exploring the same question with the adult facilitators, they pointed out-as informed by the PYD approach-that it was important to embrace a more supportive and cooperative approach, which is very different from many adults' traditional methods that are more coercive. Hence, one of the major challenges faced by adults working with young researchers was adjusting to or developing techniques that were more supportive and less intrusive in order to move from managing young researchers to a role that only facilitated them.

A recurrent question about the engagement of adult facilitators was whether the young peopleled research could be done without an adult facilitator. Interviewees from the Dhaka and Bekaa and Irbid case studies stated that the young researchers could easily conduct their own research if they were provided with the skills and tools needed. However, in order to succeed, young researchers believed adult support was necessary to ensure enabling environments- 


\section{Deconstructing the Role of Adult Facilitators}

from identifying a suitable meeting venue to helping the young researchers disseminate their findings-but this facilitation role would not compromise the young researchers' responsibilities as decision makers in terms of the methodology, data collection, analysis, and report writing. One adult facilitator from the Dhaka case study noted:

The first thing is to make them [the young researchers] comfortable. Another thing is to provide them with tools because research is very difficult . . . So, the facilitator role is very important to pass that information on . . . and make them skilled. (Adult facilitator, female, Bangladesh)

Another persistent concern was about the validity of the young people-led research based on the participation of an adult facilitator in the process. Hanadi, aged 16, female, from Lebanon, rejected this position and noted: "I can repeat any part of the report because I wrote it; I analysed the themes we discovered, we did it . . . Nobody can replace the personal experiences that are reflected in the report." Furthermore, interviewees pointed out that there is a trend to undermine the substance of this approach, of engaging an adult facilitator to support young researchers, as some critics believe that for a process to truly be young people-led, it should be entirely adult-free. However, according to interviewed adult facilitators and young researchers, there is an alternative view, based on intergenerational collaboration approaches, that argues that young researchers are able to carry out their own research, with or without adult support, and this can still be called "young people-led research" as long as the adults act only in a supportive role. One adult facilitator, summarised this position:

I believe that young people are able to lead their own research. When people ask me about that, I always say that I believe that this process can be done with the support of adults and this support does not weaken the young people-led process. Young people want support, and when this support is provided as facilitation, this help is good. (Adult facilitator, male, Lebanon)

During their interviews, adult facilitators in both the Dhaka and Bekaa and Irbid case studies were confident that they supported the process and did not manage it. They highlighted that keeping the balance between providing assistance and ensuring that the young researchers understood the basic concepts of research was a difficult assignment as the facilitator should not cross the boundary of support into management, which could be unclear. Interviewees highlighted that the strategy was to make the project easier for the young researchers, but decision making must stay in the hands of the young researchers. 


\section{Deconstructing the Role of Adult Facilitators}

\section{Power and Negotiation}

Findings from the two case studies, Dhaka and Bekaa and Irbid, show that young people-led research could bring some tensions amongst the young researchers and adult facilitators based on power relations and how these are negotiated and addressed. Consistently, across both case studies, young researchers and adult facilitators were aware of the challenges in shifting the traditional views that perpetuate the belief that adults are the experts and young people are objects of learning instead of perceiving the young researchers as subject to mutual attainments. Despite this constraint, young researchers reported feeling more empowered and skilled. Jamila summarised this position:

The research gave me confidence as I knew that we did the research and we wrote the report, I felt very confident to talk about the thing we discovered. I felt even confident in giving interviews on national television. (Jamila, aged 15, female, Lebanon)

Participants concurred that a fundamental factor in harmonising issues of power and control by adult facilitators over young researchers was capacity building. Amba, a 13-year-old girl from Bangladesh, reinforced this idea, saying: "I have learned many things. I know now about how to do interviews and focus group discussions, how to communicate with policymakers, how to collect information from policymakers, [and] how to get information from community members." A training plan provided the young researchers with the knowledge, skills, tools, and information that enabled them to take control of their research project and negotiate with their adult facilitators on an equitable basis. As a result, the Bangladeshi and Syrian young researchers emphasised that they had a sense of freedom and ownership of their projects, which could be analysed as an absence of control or limited adult authority, but also could be interpreted through another lens as they were often exposed to very restrictive environments, such as their homes and schools, where the opportunities to participate were minimal.

In terms of power and negotiation between the young researchers, the Dhaka and Bekaa and Irbid case studies have similarities in terms of their methodologies but were distinct in terms of the context and social set up that provided different views on how culture and social norms are more or less conducive to young people-led research. Data from this study evidenced some challenging issues that were deeply embedded in the traditions and cultures of the sites. For instance, in the Bekaa and Irbid case study, interview transcripts revealed that some children and young people faced a certain degree of exclusionary attitudes based on gender and ethnicity. Boys had more prominent roles in society due to patriarchal beliefs whereas the girls were perceived as less prepared. However, girls in Jordan and Lebanon pointed out that they 


\section{Deconstructing the Role of Adult Facilitators}

gave the space to boys to speak first, but they were confident that the girls were better equipped than the boys to lead the research. Put simply, they said that they always found ways to engage meaningfully in the activities without disrupting patriarchal norms. In Bangladesh, gender was not as relevant in determining participation, but religious differences were more prominent. For instance, Muslim veiled girls seemed to have less opportunities to voice their ideas due to discriminatory attitudes towards them. Interestingly, these issues were unidentified by the adult facilitators, who were unaware of the power imbalances and prejudiced views that young people held in their interactions with others. This raises important implications for adult facilitators in order to ensure that young people-led research projects do not reinforce social inequalities and unfair power dynamics amongst children and young people. Another notable difference was the refugee status of participants in the Bekaa and Irbid case study versus poverty in Dhaka case. Interviews with young Syrian refugee researchers showed that the young people-led research was an empowering experience that helped them to overcome the pain caused by their refugee status in countries where they feel unwelcome. In the Dhaka case study, young researchers did not experience a displacement, but they felt marginalised due to poverty, and they highlighted that the project provided a space to feel part of the society.

Returning to the decision-making process, data from the Dhaka and Bekaa and Irbid case studies show that young researchers felt confident that they were decision makers and active in negotiating power with their facilitators during the different phases of their research processes. Safa, a 14-year-old girl from Jordan, noted: "The best was the freedom. Freedom to decide, freedom to participate, freedom to think, freedom to say no. They [the adult facilitators] even asked us if they can take a photo of us, and we were free to say yes or no." The young researchers signalled that they intensely debated every decision taken during the research and the adult facilitators did not intervene in their choices. Remarkably, the presence of the adult facilitator in the young researchers' meetings was not considered a critical factor to defining the ownership of the research project; young researchers held that their power and ability to negotiate were the underpinning principles of their work.

Nevertheless, in my conversations with the young researchers from the Dhaka and Bekaa and Irbid case studies, they argued that they found some tensions and power issues regarding certain project decisions where they did not have much control, for instance, issues around safeguarding standards, anonymity, and budget. Adult facilitators contested this claim, stating that the young researchers' safety and protection were not negotiable standards and that their decisions were made in line with institutional rules. For instance, parents/guardians and young researchers were asked to provide informed consent to join the research projects. Data from 


\section{Deconstructing the Role of Adult Facilitators}

the Dhaka and Bekaa and Irbid case studies show that the young researchers did not always understand the safeguarding decisions, on which one might infer that these measures were not well-explained. Hence, some judgements may have caused conflicts and feelings of powerlessness in the lack of negotiation. Nevertheless, interviews with research participants confirmed that these tensions did not have a negative impact on the research projects as the intergenerational trust relationship and mutual respect were underlined as one of the projects' highlights. Data collected in both case studies, however, do not provide evidence of whether these issues were discussed and accepted by the young researchers as they considered them useful or if they were just informed of the facilitators' choices and followed the imposed decisions because they did not have a solid argument to defend their positions.

In order to determine the challenging interactions between young researchers and supporting adults, Johnson (2011) argues that it is critical to examine organisational definitions of young people's participation to understand how they might affect the different levels of participation and the final outcomes. In this regard, World Vision (2015) outlines their goal for young people's participation as "excelling in creating and advocating for enabling environments that empower children and young people as social actors, advocates and partners for child wellbeing" (p.9). This policy statement reflects the ways the organisation and its staff members are mandated to position young people as partners and rights holders, creating spaces for them to carry out their own initiatives and negotiating spaces for decision making without imposing their own institutional agenda. In this context, an "enabling environment" is understood as one where the views, opinions, and perspectives of young people are sought, listened to, and respected at all levels of the organisation and wider society. However, a pragmatic question is how the young researchers-are all from vulnerable and marginalised populations-are able to negotiate their engagement in the projects with a large organisation that controls the resources and the implementation of their initiatives in the field. As an answer, the adult facilitators explained that the young people-led research as a methodology and project did not exclude the organisation and its staff members from the process, but regulated the young researchers' level of engagement in decision making in order to ensure that they completely owned their research project.

\section{Interpersonal Connections}

Another finding that emerged from the data collected from the Dhaka and Bekaa and Irbid case studies was the role of the interpersonal connections between the young researchers and adult facilitators and how these relations had an impact on their research project. This evidenced that 


\section{Deconstructing the Role of Adult Facilitators}

young people-led research—as a participatory project-was fundamentally relational and reliant on the abilities of adult facilitators to engage with the young researchers in a meaningful fashion. Data show that when the adult facilitators were more engaging, the young researchers felt respected, appreciated, and loved, and as emotions are give-and-take by nature, the adult facilitators perceived similar reciprocal feelings. According to the findings of this study, the personal characteristics of the adult facilitator and the level of engagement with the young people appears to be crucial in the accomplishment of the project. Almira, a 15-year-old girl from Lebanon, noted: "We felt free to say whatever we want to say, to express whatever we want. Not like in school where we have teachers; this was like we were friends, like friends working together."

In exploring how these interpersonal relations were nurtured, interviewees pointed out that the personal characteristics of the adult facilitators were central to creating these emotional bonds, especially when they positioned themselves as part of the participatory process and not as an external party. In this case, participants noted that the rapport was established through informal conversations, such as asking questions about school, family, and social activities. In turning the question to the young researchers, they mentioned that the personality of the adult facilitator was important for them as they felt welcomed and supported. Furthermore, they said this was a relevant factor for them to remain involved in the project. This echoes findings from Cornish (2010) that reveal that young people stay engaged in participatory projects when they perceive they are treated nicely and respectfully and leave activities due to bad experiences with facilitators who are rude, disrespectful, and privilege some groups of young people over others.

Young people in the two case studies valued certain characteristics associated with positive emotional responses due to the facilitators' personalities and commented on the outward expressions of the facilitators. Young researchers recalled the main qualities and characteristics of their facilitators as tenderness; supportiveness; and being caring, sympathetic, understanding, and non-manipulative, which made them feel valued, respected, and encouraged to participate in the project.

Everything was good. He [the facilitator] helped us in many things; he was always trying to see who needed help. Even when we were divided in groups, he helped every group with their needs. He was always smiling, and we felt so relaxed. (Farid, aged 17, male, Lebanon) 


\section{Deconstructing the Role of Adult Facilitators}

The relationship and support provided by the adult facilitators was highly valued by the participants, in contrast to their views of other adult professionals working with young people whom they perceived as lacking the skills and tools to work with young people. A 16-year-old Syrian girl, Abir, explained: "In the support that he [the facilitator] was doing, everything was great. I didn't feel at all he was behaving as a teacher; I felt he was like a friend." When asked whether these good characteristics of an adult facilitator's personality were the norm or the exception, young researchers responded that few facilitators were sensitive to their needs and most staff members working with them were serious, boring, and hard to understand. This example illustrates that facilitators' personal characteristics are critical to building rapport, empathy, and positive emotional connections to help young people feel safe, comfortable, amused, and supported.

It was evident from the data that the process of young people-led research was emotional for both the young researchers and adult facilitators. A young participant explained that they liked the company of the facilitator and they expected him to stay with them for a long time and not just one activity. Jamila, 14-years-old girl in Jordan, said: "I want to have a new project now. Don't leave us alone." This account reflects the need for closure in a sensitive, intercultural, and supportive way. A closing process cannot be underestimated as this enables young people to understand that the end of a process may mean that they will not see their adult facilitators anymore or may interact with them in a different capacity.

\section{Conclusions}

Young people-led research appears to offer an alternative to generating knowledge and addressing some social inequalities and power imbalances that often exclude young people from decision making. As a participatory project, this approach facilitates the engagement of largely underrepresented and excluded groups in the construction of their own accounts as a means of producing knowledge. This shift is the result of moving away from beliefs that perceive adult professionals as the only ones able to create knowledge to a position that recognises young people as competent social actors with the skills and competencies to engage in research. As the young people-led research was conceived as a collaborative project, this study offers views on how adult facilitators' engagement can be a substantial contributing factor to this approach; yet, at the same time, could also bring some potentially conflicting issues that could undermine the process, if not analysed and resolved. A lack of a critical stance on these issues could leave young researchers locked between two positions: one that considers them as competent individuals able to carry out research and another that limits their abilities to engage 


\section{Deconstructing the Role of Adult Facilitators}

based on the belief that they are not prepared and are unable to make judgments for themselves. This study shows that the former option worked well in both the Dhaka and Bekaa and Irbid case studies.

This article discusses how the bonding and relationships between adult facilitators and young researchers were fundamental in ensuring a long-term engagement and led to satisfactory results as influenced by the PYD framework. The young researchers and adult facilitators developed relationships that made an impact on the commitment of the young researchers to work together. As such, they enjoyed their experience as part of the group as well as the mutual learning that increased the skills and knowledge for both the adults and young researchers. The focus on interpersonal relationships resonates with the need to invest time and efforts to develop rapport and build interconnections of mutual trust and equal respect between young researchers and adult facilitators.

The study reveals that these interactions are blurred and complex as the boundaries between supporting and managing the young researchers can sometimes be undistinguishable. The case studies show that the young researchers confidently considered the research as their own project as they perceived that they controlled all aspects of the process from developing the questions to data collection to writing the final report. Nevertheless, the young people-led research approach raises challenging issues, such as negotiating authority and dealing with power decisions, which could exacerbate inequality in participation, if not acknowledged. The presence of a skilled and well-trained adult facilitator provides guidance and support, but a key question is whether the control over the research remains with the young researchers and not with the adult facilitator.

Looking forward, the findings of this study suggest that adult facilitators must create enabling environments to address complex issues such as power; control; and hierarchy as a result of age, experience, and social position. This implies the development of mechanisms and strategies that enhance optimal working relationships between the young researchers and adult facilitators, which are founded in respect for the different types of experiences and expertise that individuals have. However, these relationships involve continuous negotiation in order to shift the control that adult facilitators have over the young researchers, enabling them to generate knowledge based on exchange and mutual learning. If these issues are ignored or neglected, differences could exacerbate inequality in participation. 
Journal of Youth Development | http://jyd.pitt.edu/ | Vol. 16 Issue 2-3 DOI 10.5195/jyd.2021.1034

Deconstructing the Role of Adult Facilitators

\section{Acknowledgments}

The author would like to thank the generous contributions of children and young people and adults professionals who contributed with their rich insights. Many thanks to the anonymous reviewers, and Kay Tisdall for discussions related to childhood studies discourse.

\section{References}

Alanen, L. (2016). Intersectionality and other challenges to theorizing childhood. Childhood, 23(2), 157171. https://doi.org/10.1177/0907568216631055

Alderson, P. (2015). Reforms to healthcare systems and policies: Influences from children's rights. In: A. B. Smith (Ed.), Enhancing children's rights (pp. 17-32). https://doi.org/10.1057/9781137386106 2

Alderson, P., \& Morrow, V. (2004). Ethics, social research and consulting with children and young people. Barnardo's.

Ansell, N., Robson, E., Hajdu, F., \& van Blerk, L. (2012). Learning from young people about their lives: Using participatory methods to research the impacts of AIDS in southern Africa. Children's Geographies, 10(2), 169-186. https://doi.org/10.1080/14733285.2012.667918

Anyon, Y., Bender, K., Kennedy, H., \& Dechants, J. (2018). A systematic review of youth participatory action research (YPAR) in the United States: Methodologies, youth outcomes, and future directions. Health Education \& Behavior, 45(6). SAGE, 865-878. https://doi.org/10.1177/1090198118769357

Ardoin, N. M., Castrechini, S., \& Hofstedt, M. K. (2014). Youth-community-university partnerships and sense of place: Two case studies of youth participatory action research. Children's Geographies, 12(4), 479-496. https://doi.org/10.1080/14733285.2013.827872

Benson, P. L., Scales, P. C., Hamilton, S. F., \& Sesmal, A., Jr. (2007) Positive youth development: Theory, research, and applications. John Wiley \& Sons. https://doi.org/10.1002/9780470147658.chpsy0116

Bessell, S. (2009). Children's participation in decision-making in the Philippines: Understanding the attitudes of policy-makers and service providers. Childhood, 16(3), 299-316.

\section{https://doi.org/10.1177/0907568209335305}

Blaikie, N. W. (2009). Designing social research. Polity.

Cahill, C. (2007). Including excluded perspectives in participatory action research. Design Studies, 28(3), 325-340. https://doi.org/10.1016/j.destud.2007.02.006 
Caputo, V. (2017). Children's participation and protection in a globalised world: Reimagining 'too young to wed' through a cultural politics of childhood. The International Journal of Human Rights, 21(1), 76-88. https://doi.org/10.1080/13642987.2016.1248124

Cornish, N. (2010). Children's voices: Gaps in inclusion. World Vision International.

Cuevas-Parra, P. (2015). Becoming researchers: A simple guide for children and young people who want to carry out social research. World Vision International. Retrieved May 10, 2020, from https://www.wvi.org/sites/default/files/WV-Becoming\%20Researchers\%2013.03.2017.pdf

Cuevas-Parra, P., \& Tisdall, E. K. M. (2019.) Child-led research: Questioning knowledge. Social Sciences, 8(2), 44. https://doi.org/10.3390/socsci8020044

Davis, J. M. (2009). Involving children. In E. K. M. Tisdall, J. M. Davis , \& M. Gallagher (Eds.), Research with children and young people: Research design, methods and analysis. SAGE. http://dx.doi.org.libezproxy.open.ac.uk/10.4135/9781446268315

Fleming, J. (2012). Young people's participation - Where next? Children \& Society, 276), 484-495. https://doi.org/10.1111/j.1099-0860.2012.00442.x

Gray, D. (2009). Doing research in the real world. SAGE.

Guest, G., MacQueen, K. M., \& Namey, E. E. (2012). Applied thematic analysis. SAGE. Hampshire, K., Porter, G., Owusu, S., Mariwah, S., Abane, A., Robson, E., Munthali, A., Mashiri, M., Maponya, G., \& Bourdillon, M. (2012). Taking the long view: temporal considerations in the ethics of children's research activity and knowledge production. Children's Geographies, 10(2), 219232. https://doi.org/10.1080/14733285.2012.667921

Hordijk, M., \& Baud, I. (2006). The role of research and knowledge generation in collective action and urban governance: How can researchers act as catalysts? Habitat International, 30(3), 668-689. https://doi.org/10.1016/j.habitatint.2005.04.002

James, A. (2007). Giving voice to children's voices: Practices and problems, pitfalls and potentials. American Anthropologist, 109(2), 261-272. https://doi.org/10.1525/aa.2007.109.2.261

James, A., \& James, A. L. (2012). Key concepts in childhood studies. SAGE.

Johnson, V. (2011). Conditions for change for children and young people's participation in evaluation: 'Change-scape'. Child Indicators Research, 4(4), 577-596. https://doi.org/10.1007/s12187-010$\underline{9099-6}$

Johnson, V., Hart, R. A., \& Colwell, J. (2014). Steps to engaging young children in research. University of Brighton, Education Research Centre and the Bernard van Leer Foundation.

Kina, V. J. (2012). What we say and what we do: Reflexivity, emotions and power in children and young people's participation. Children's Geographies, 10(2), 201-218.

https://doi.org/10.1080/14733285.2012.667920 
Konstantoni, K., \& Emejulu, A. (2017). When intersectionality met childhood studies: The dilemmas of a travelling concept. Children's Geographies, 15(1), 6-22. https://doi.org/10.1080/14733285.2016.1249824

Mackenzie, J., Tan, P.-L., Hoverman, S., \& Baldwin, C. (2012). The value and limitations of participatory action research methodology. Journal of Hydrology, 474, 11-21.

https://doi.org/10.1016/j.jhydrol.2012.09.008

Mayall, B. (2000). The sociology of childhood in relation to children's rights. The International Journal of Children's Rights, 8, 243-259.

Michail, S., \& Kellett, M. (2015). Child-led research in the context of Australian social welfare practice: Child-led research. Child \& Family Social Work, 20(4), 387-395.

https://doi.org/10.1111/cfs. 12087

Morgan, D. L. (2012). Focus groups and social interaction. In J. F. Gubrium, J., A. Holstein, A. B. Marvasti, \& K. D. McKinney (Eds.), The SAGE handbook of interview research: The complexity of the craft. SAGE.

Newell, S., Graham, A., Fitzgerald, R., Behrend, Z, \& Malins, T. (2012). Child-led research: A pilot of the Today \& Tomorrow research program. UnitingCare Burnside.

Participation Works. (2009). The explorers: Practitioner-led research case study. Retrieved November 2, 2019, from http://www.participationworks.org.uk/resources/the-explorers-practitioner-ledresearch-case-study/

Percy-Smith, B. (2010.) Councils, consultations and community: Rethinking the spaces for children and young people's participation. Children's Geographies, 8(2), 107-122.

https://doi.org/10.1080/14733281003691368

Pinkney, S. (2011). Participation and emotions: Troubling encounters between children and social welfare professionals: Participation and emotions for children and social welfare professionals. Children \& Society, 25(1), 37-46. https://doi.org/10.1111/j.1099-0860.2009.00261.x

Plows, V. (2012). Conflict and coexistence: Challenging interactions, expressions of agency and ways of relating in work with young people in the minority world. Children's Geographies, 10(3), 279-291. https://doi.org/10.1080/14733285.2012.693378

Porter, G., Townsend, J., \& Hampshire, K. (2012). Children and young people as producers of knowledge. Children's Geographies, 10(2), 131-134. https://doi.org/10.1080/14733285.2012.667915

Prout, A., \& James, A. (1990). A new paradigm for the sociology of childhood? In A. Prout \& A. James (Eds.), Constructing and reconstructing childhood: Contemporary issues in the sociological study of childhood (pp. 7-33). Routledge Falmer.

Punch, S. (2002). Interviewing strategies with young people: the 'secret box', stimulus material and taskbased activities. Children \& Society, 16(1), 45-56. https://doi.org/10.1002/chi.685 
Journal of Youth Development | http://jyd.pitt.edu/ | Vol. 16 Issue 2-3 DOI 10.5195/jyd.2021.1034

Deconstructing the Role of Adult Facilitators

Punch, S. (2012). Hidden struggles of fieldwork: Exploring the role and use of field diaries. Emotion, Space and Society, 5(2), 86-93. https://doi.org/10.1016/j.emospa.2010.09.005

Ritchie, J., \& Lewis, J. (2003). Qualitative research practice: A guide for social science students and researchers. Sage.

Rodó-de-Zárate, M. (2015). Young lesbians negotiating public space: An intersectional approach through places. Children's Geographies, 13(4), 413-434. https://doi.org/10.1080/14733285.2013.848741

Sharpe, D. (2015). Young people's involvement in policy research. Children's Geographies, 13(2), 240248. https://doi.org/10.1080/14733285.2014.978488

Shier, H. (2015). Children as researchers in Nicaragua: Children's consultancy to transformative research. Global Studies of Childhood, 5(2), 206-219. https://doi.org/10.1177/2043610615587798

Skelton, T. (2008). Research with children and young people: Exploring the tensions between ethics, competence and participation. Children's Geographies, 6(1): 21-36. https://doi.org/10.1080/14733280701791876

Spalding, V. (2012). We are researchers - child-led research: Children's voice and educational value. AQA Centre for Education Research and Policy. Retrieved August 22, 2019, from https://cerp.aqa.org.uk/sites/default/files/pdf upload/CERP-RP-VS-01112011.pdf

Spyrou, S. (2011). The limits of children's voices: From authenticity to critical, reflexive representation. Childhood, 18(2), 151-165. https://doi.org/10.1177/0907568210387834

Thomas, N. (2015). Children and young people's participation in research. In T. Gal \& B. F. Duramy (Eds.), International perspectives and empirical findings on child participation: From social exclusion to child-inclusive policies (pp. 89-108). Oxford University Press.

Tisdall, E. K. M. (2015). Children and young people's participation: A critical consideration of Article 12. In W. Vandenhole, E. Desmet, D. Reynaert \& S. Lembrechts (Eds.), Routledge international handbook of children's rights studies (pp. 185-200). Routledge.

Tisdall, E. K. M. (2017). Conceptualising children and young people's participation: Examining vulnerability, social accountability and co-production. The International Journal of Human Rights, 21(1), 59-75. https://doi.org/10.1080/13642987.2016.1248125

Tisdall, E. K. M., \& Punch, S. (2012). Not so 'new'? Looking critically at childhood studies. Children's Geographies, 10(3), 249-264. https://doi.org/10.1080/14733285.2012.693376

Törrönen, M. L., \& Vornanen, R. H. (2014). Young people leaving care: Participatory research to improve child welfare practices and the rights of children and young people. Australian Social Work, 671), 135-150. https://doi.org/10.1080/0312407X.2013.868012

UN Committee on the Rights of the Child. (2009). General comment no. 12: The right of the child to be heard. Retrieved November 10, 2018, from https://www2.ohchr.org/english/bodies/crc/docs/AdvanceVersions/CRC-C-GC-12.pdf 
Journal of Youth Development | http://jyd.pitt.edu/ | Vol. 16 Issue 2-3 DOI 10.5195/jyd.2021.1034 Deconstructing the Role of Adult Facilitators

White, G. W., Suchowierska, M., \& Campbell, M. (2004). Developing and systematically implementing participatory action research. Archives of Physical Medicine and Rehabilitation, 85, 3-12. https://doi.org/10.1016/j.apmr.2003.08.109

World Vision International. (2015). Children and young people strategic direction: 2015-2020. Retrieved April 15, 2020, from https://www.wvi.org/child-participation/publication/world-visions-child-andyouth-participation-strategic-direction-0

Wyness, M. (2009). Adult's involvement in children's participation: Juggling children's places and spaces. Children \& Society, 23(6), 395-406. https://doi.org/10.1111/j.1099-0860.2008.00181.x

Yardley, A. C. (2011). Children as experts in their own lives: Reflections on the principles of creative collaboration. Child Indicators Research, 4(2), 191-204. https://doi.org/10.1007/s12187-0109102-2

YouthPower Learning. (2020). Experts, researchers, and mentors: The many forms of youth leadership. Retrieved January 30, 2021, from https://www.youthpower.org/sites/default/files/YouthPower/files/resources/YPL\%20GUCyouth\%20engage\%20brief\%20final.pdf 